\title{
Cathepsin $L$ in metastatic bone disease: therapeutic implications
}

\author{
Gaetano Leto*, Maria Vittoria Sepporta, Marilena \\ Crescimanno, Carla Flandina and Francesca Maria \\ Tumminello \\ Laboratory of Experimental Chemotherapy, Department \\ of Surgery and Oncology, Policlinico Universitario \\ P. Giaccone, I-90127 Palermo, Italy \\ * Corresponding author \\ e-mail: gleto@unipa.it
}

\begin{abstract}
Cathepsin L is a lysosomal cysteine proteinase primarily devoted to the metabolic turnover of intracellular proteins. However, accumulating evidence suggests that this endopeptidase might also be implicated in the regulation of other important biological functions, including bone resorption in normal and pathological conditions. These findings support the concept that cathepsin L, in concert with other proteolytic enzymes involved in bone remodeling processes, could contribute to facilitate bone metastasis formation. In support of this hypothesis, recent studies indicate that cathepsin L can foster this process by triggering multiple mechanisms which, in part, differ from those of the major cysteine proteinase of osteoclasts, namely cathepsin K. Therefore, cathepsin L can be regarded as an additional target in the treatment of patients with metastatic bone disease. This review discusses the clinical and therapeutic implications related to these findings.
\end{abstract}

Keywords: bone metastasis; cancer; cathepsin K; cathepsin $\mathrm{L}$; cysteine proteinases; proteinase inhibitors.

\section{Introduction}

Bone metastasis is a frequent complication of certain solid tumors (Mundy, 2002). Patients with metastatic bone disease are at high risk of skeletal related events (SREs) such as pathological fracture, nerve compression syndrome, debilitating bone pain and hypercalcemia (Mundy, 2002). Current clinical treatments of this pathological condition are merely palliative and do not provide a life-prolonging benefit to metastatic patients (Mundy, 2002; Lipton, 2007). Consequently, in recent years, consistent efforts have been directed to the discovery of new molecules which could be effective to inhibit SREs and to prevent bone metastasis formation (Mundy, 2002; Lipton, 2007). These studies have identified, as possible molecular targets, several proteolytic enzymes including some cysteine proteinases, which appear to be implicated in the regulation of normal and pathological bone turnover (Maciewicz et al., 1990; Brage et al., 2005; Everts et al., 2006; Solau-Gervais et al., 2007; Charni-Ben Tabassi et al., 2008; Wilson and Singh, 2008). Among cysteine proteinases, cathepsin $\mathrm{K}$, an endopeptidase predominantly expressed in osteoclasts, is currently thought to play a major role in pathological conditions associated with an altered bone resorption including cancer induced osteolysis (Kiviranta et al., 2005; Le Gall et al., 2008; Wilson and Singh, 2008). Therefore, many studies in the field of lysosomal cysteine proteinases and bone metastases, undertaken in the past decade, have focused their attention mainly on this enzyme, perhaps underscoring the potential involvement of other proteinases of this family and, in particular, that of cathepsin L, a lysosomal endopeptidase which participates in tissue degradation and extracellular matrix remodeling and which makes a significant contribution to the degradation of bone matrix (Maciewicz et al., 1990; Hill et al., 1994; Li et al., 2004; Brage et al., 2005; Kiviranta et al., 2005; Everts et al., 2006; Charni-Ben Tabassi et al., 2008; Lion et al., 2009; Ogawa et al., 2009). By contrast, the hypothesis that cathep$\sin \mathrm{L}$ can contribute to bone metastasis formation is supported by many experimental and clinical observations, which highlight that the expression levels of this proteinase are deregulated in bone diseases with an elevated bone turnover (Hill et al., 1994; Park et al., 1996; Söderström et al., 2001; Lang et al., 2004; Lindeman et al., 2004; Schedel et al., 2004; Kido et al., 2007; Solau-Gervais et al., 2007; Husmann et al., 2008; Wilson and Singh, 2008) and that the administration of selective cathepsin L antagonists can inhibit and prevent cancer induced bone resorption in mice (Hill et al., 1994; Katunuma et al., 2002a,b; Long and Chagno-

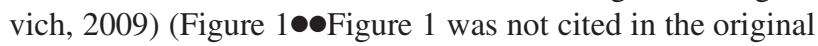

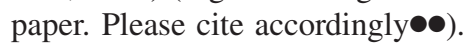

\section{Cathepsin L structure and function}

Cathepsin L (EC 3.4.22.15) is a lysosomal cysteine endopeptidase synthesized as a $39-\mathrm{kDa}$ inactive precursor form which is normally activated in the acidic environment of lysosomes (Chauhan et al., 1993; Rawlings et al., 2010). The active form of this enzyme consists of a heavy chain of approximately $21 \mathrm{kDa}$ and a light chain of approximately 5 kDa (Chauhan et al., 1993; Rawlings et al., 2010). In humans, the gene encoding for cathepsin L (CTSL) maps to chromosome 9q21-q22 and contains eight exons and seven introns (Chauhan et al., 1993; Rawlings et al., 2010). This locus is adjacent to another gene coding for a cathepsin Llike protein, namely cathepsin L2 (also known as cathepsin V) which share a $80 \%$ protein sequence identity with cathep- 


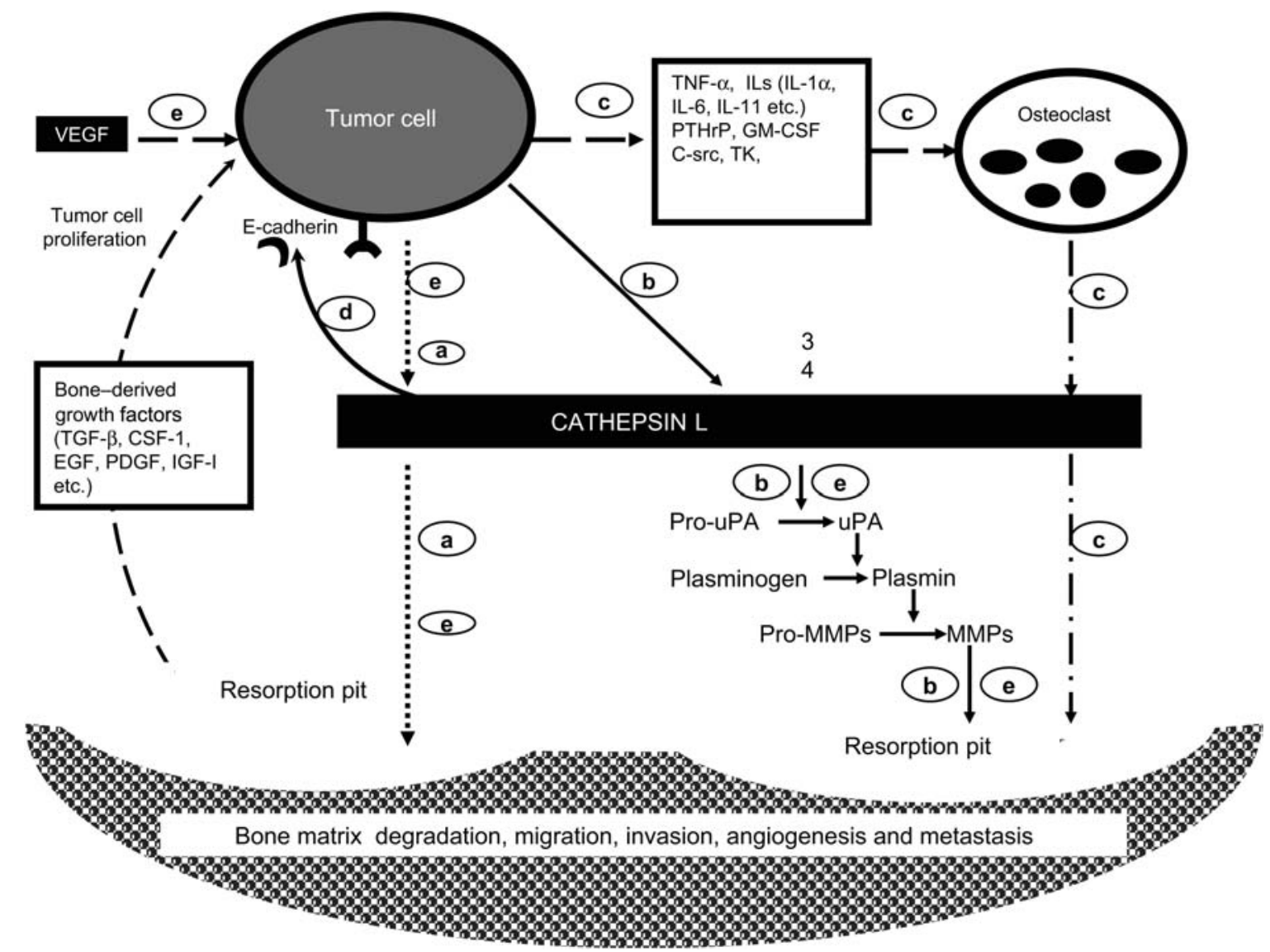

Figure 1 Schematic representation of the possible, multiple mechanisms by which cathepsin L could facilitate bone metastasis formation. (A) Cathepsin L secreted by cancer cells can directly degrade bone extracellular matrix thus promoting tumor cells invasion and metastasis. (B) Additionally, the enzyme can indirectly promote this process by triggering the activation latent precursor forms of other enzymes involved in the metastatic cascade such as matrix metalloproteinases (MMPs) and urokinase type plasminogen activator (uPA). (C) Following the upregulation of cathepsin L by proinflammatory cytokines which promote bone pit formation, the enzyme can contribute to degrade bone matrix by the mechanisms described above. (D) Similar to other proteinases such as cathepsin B and MMPs, cathepsin L can degrade E-cadherin, an adhesion molecule which is downregulated in metastatic tumor cells, thus enhancing their migratory and invasive ability. (E) Finally, cathepsin L might also facilitate bone metastasis formation by promoting tumor angiogenesis by multiple mechanisms: (i) activation of latent forms of proteolytic enzymes promoting tumor neovascularization such as uPA and MMPs and (ii) upregulation VEGF in tumor cells. See text for details and related references.

sin $\mathrm{L}$ and a $75 \%$ amino acid sequence identity with mouse cathepsin L (Brömme et al., 1999). However, despite their high amino acid sequence homology, these enzymes differ in their tissue distribution and biological functions. In fact, whereas cathepsin L is expressed in most eukaryotic cells, cathepsin $\mathrm{V}$ expression is restricted to a limited number of tissues and cells, namely corneal epithelium, epidermis, testes, thymus and activated macrophages (Chauhan et al., 1993; Brömme et al., 1999; Bernard et al., 2003; Yasuda et al., 2004). Furthermore, cathepsin L is mainly involved in the metabolic turnover of intracellular and secreted regulatory proteins (Chauhan et al., 1993; Collette et al., 2004; Rawlings et al., 2010), whereas the biological effects of cathepsin V appear to be confined to some specific immunological functions and to the regulation of epidermis homeostasis (Hagemann et al., 2004; Yasuda et al., 2004). The intracellular activity of these proteinases is regulated by endogenous inhibitors of the cystastins superfamily (Turk et al., 2008). However, the biological functions of cathepsin L are not merely confined to the breakdown of intracellular proteins but also comprise other important processes such as apoptosis and tissue homeostasis (Hagemann et al., 2004; Potts et al., 2004; Stoka et al., 2007; Luft, 2009; Dennemärker et al., 2010; Lankelma et al., 2010), immune response (Hsing and Rudensky, 2005; Zavasnik-Bergant and Turk, 2007), activation of latent forms of other proteolytic enzymes (Everts et al., 2006; Laurent-Matha et al., 2006; AbboudJarrous et al., 2008) and hormone production and processing (Yasothornsrikul et al., 2003; Funkelstein et al., 2008). The active role of cathepsin $\mathrm{L}$ in some of these processes is further confirmed by in vivo studies which show that cathepsin L-deficient mice exhibit distinct defects in MHC class II processing in thymic cortical epithelial cells, impaired myocardial functions, epithelial hyperplasia, hypotrichosis and 
progressive hair loss (Reinheckel et al., 2001; Hagemann et al., 2004; Potts et al., 2004; Luft, 2009) and reduced production and secretion of neurotransmitters and hormones (Yasothornsrikul et al., 2003; Funkelstein et al., 2008).

\section{Cathepsin $\mathrm{L}$ in bone remodeling}

In addition to the biological functions described above, experimental evidence suggests that cathepsin L can also be implicated in the regulation of bone resorption in normal and pathological conditions (Table 1). This hypothesis is supported by many biochemical and immunohistochemical studies which show that this proteinase is present in rodent osteoclasts (Maciewicz et al., 1990; Rifkin et al., 1991; Ohsawa et al., 1993; Tagami et al., 1994; Kakegawa et al., 1995; Furuyama and Fujisawa, 2000a; Goto et al., 2003; Czupalla et al., 2006) and in human osteoclasts (Nakase et al., 2000; Ishibashi et al., 2001; Li et al., 2004; Everts et al., 2006; Perez-Amodio et al., 2006; Charni-Ben Tabassi et al., 2008) where it could contribute to degrade several components of bone extracellular matrix (Maciewicz et al., 1990; Li et al., 2004; Everts et al., 2006; Charni-Ben Tabassi et al., 2008; Lion et al., 2009; Ogawa et al., 2009) (Table 1). Furthermore, immunoelectron microscopy studies reveal that, in rat osteoclasts, cathepsin L is closely associated with the collagen fibrils and bone matrix under the ruffle border of these cells (Goto et al., 2003). Although the expression levels of this proteinase in osteoclasts result in highly variable and are much more lower than that of cathepsin K (Rifkin et al.,
1991; Drake et al., 1996; Everts et al., 2006; Perez-Amodio et al., 2006), it has been shown that, in vitro, the intracellular activity and secretion of cathepsin L in these cells could be upregulated following the release, in the microenvironment, of cytokines which modulate bone resorption such as parathyroid hormone (PTH) (Tagami et al., 1994; Kakegawa et al., 1995; Furuyama and Fujisawa, 2000b), c-Src tyrosine kinase (c-Src-TK) (Furuyama and Fujisawa, 2000a), interleukin-1 $\alpha$ (IL-1 $\alpha)$ (Furuyama and Fujisawa, 2000b), interleukin-6 (IL-6) (Damiens et al., 2000; Furuyama and Fujisawa, 2000b), tumor necrosis factor- $\alpha$ (TNF- $\alpha$ ) (Kakegawa et al., 1995; Furuyama and Fujisawa, 2000b; Katunuma et al., 2002a; Hashimoto et al., 2006) and interferon- $\gamma$ (Pang et al., 2005). In particular, some of these studies show that PTH and TNF- $\alpha$ can increase the secretion of a precursor form of cathepsin L into culture medium from a bone cell mixture (Tagami et al., 1994; Kakegawa et al., 1995; Furuyama and Fujisawa, 2000a,b; Katunuma et al., 2002a). The pro-enzyme can then be rapidly converted, under acid conditions, in the mature form and can promote bone pit formation (Kakegawa et al., 1995; Furuyama and Fujisawa, 2000b). Interestingly, these effects are inhibited by E-64, a non-selective cysteine proteinase inhibitor but not by CA074, a specific inhibitor of cathepsin B (Furuyama and Fujisawa, 2000b; Montaser et al., 2002). By contrast, the possible involvement of cathepsin $\mathrm{L}$ in bone resorption is further supported by in vivo studies which show that cathepsin L knockout mice (B6;129-Ctsl ${ }^{\text {tm1Alpk }}$ ) present alterations in bone structure (Potts et al., 2004). However, these alterations are different from the osteopetrotic phenotype type

Table 1 Cathepsin L in bone.

\begin{tabular}{|c|c|}
\hline Study & References \\
\hline Present in rodent osteoclasts & $\begin{array}{l}\text { Maciewicz et al., 1990; Rifkin et al., 1991; } \\
\text { Ohsawa et al., 1993; Tagami et al., 1994; } \\
\text { Kakegawa et al., 1995; } \\
\text { Furuyama and Fujisawa, 2000a; } \\
\text { Goto et al., 2003; Czupalla et al., } 2006\end{array}$ \\
\hline Present in human osteoclasts & 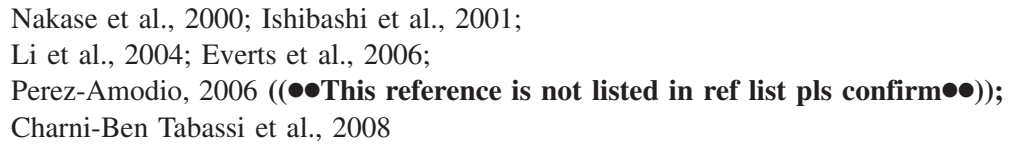 \\
\hline Colocalization with the collagen & Goto et al., 2003 \\
\hline
\end{tabular}

fibrils and bone matrix under the ruffle border of rat osteoclasts Upregulation of osteoclast cathepsin L activity and secretion by cytokines promoting bone resorption (PTH), c-Src-TK, IL-1 $\alpha$, IL-6, TNF- $\alpha$ Degradation of bone matrix proteins

Altered bone structure in cathepsin L knockout mice Altered expression levels in non-malignant pathological conditions associated with an enhanced bone turnover

Tagami et al., 1994; Kakegawa et al., 1995;

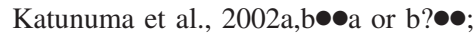

Furuyama and Fujisawa, 2000a,b;

Pang et al., 2005; Hashimoto et al., 2006

Maciewicz et al., 1990; Kakegawa et al., 1995;

Everts et al., 2006; Charni-Ben Tabassi et al., 2008;

Lion et al., 2009; Ogawa et al., 2009

Potts et al., 2004; Kiviranta et al., 2005;

Everts et al., 2006

Keyszer et al., 1998; Lang et al., 2004;

Potts et al., 2004; Schedel et al., 2004;

Kido et al., 2007; Solau-Gervais et al., 2007 
observed in cathepsin K-deficient mice (Potts et al., 2004; Kiviranta et al., 2005). In particular, the histomorphometric examination of the bone in the cathepsin L heterozygote and homozygote mice shows a significant reduction of trabecular bone volume, but not that of cortical volume, compared with wild type mice (Potts et al., 2004). This effect was associated with a concomitant reduction in the number of osteoclasts eroding the mineralized cartilagine $\bullet$ Should this be cartilage?•• (Potts et al., 2004). These findings could fit well with previous observations from other studies which suggest a specific role for cathepsin $\mathrm{L}$ in the process of endochondrial ossification (Nakase et al., 2000; Uusitalo et al., 2000) and further support the hypothesis of a complementary role of this protease in bone resorption (Kakegawa et al., 1995; Furuyama and Fujisawa, 2000a,b; Potts et al., 2004; Kiviranta et al., 2005; Everts et al., 2006; Schurigt et al., 2008; Long and Chagnovich, 2009).

\section{Cathepsin L in metastatic bone disease}

Accumulating evidence suggests that cathepsin L, in concert with other proteinases such as cathepsin B, matrix metalloproteinases (MMPs) and, urokinase type plasminogen activator (uPA), could facilitate cancer progression (Chauhan et al., 1991; Wilson and Singh, 2008; Lankelma et al., 2010). This hypothesis is sustained by a consistent body of experimental and clinical observations which show that the intracellular expression levels of cathepsin L are upregulated in many human tumors and that this phenomenon is associated with the onset of more aggressive tumor phenotypes and/or with a poor clinical outcome (Chauhan et al., 1991; Tumminello et al., 1996; Lankelma et al., 2010). It is noteworthy that altered expression levels of cathepsin L have also been observed, in particular, in some primary bone tumors such as osteosarcoma (Park et al., 1996; Haeckel et al., 1999; Damiens et al., 2000; Kirschke et al., 2000; Krueger et al., 2001; Husmann et al., 2008), giant cell tumor of the bone (Park et al., 1996; Lindeman et al., 2004), multiple myeloma (Spens and Haggstrom, 2005), chondrosarcomas (Park et al., 1996; Söderström et al., 2001), in tumors which preferentially metastasize to the bone such as breast cancer (Harbeck et al., 2001; Zajc et al., 2002; Caserman et al., 2006), prostate cancer (Friedrich et al., 1999; Colella et al., 2004; Goo et al., 2009), lung cancer (Kayser et al., 2003), laryngeal cancer (Russo et al., 1995), melanoma (Yang and Cox, 2007), oral cancer (Erdem et al., 2007) and in bone metastases (Park et al., 1996). These findings are intriguingly regarding a possible involvement cathepsin L, also in bone metastasis formation. By contrast, several experimental data support this hypothesis. For instance, Damiens et al. (2000) reported that human osteosarcoma cell lines MG-63 and SaOS2 produced cathepsin L. Interestingly, the intracellular levels of this proteinase were increased by proinflammatory cytokines promoting bone resorption such as IL-1 $\beta$, IL-6 or TNF- $\alpha$ (Kawamata et al., 1997; Katunuma et al., 2002a; Kwan Tat et al., 2004; Blanchard et al., 2009). More recently, Husmann et al. (2008) showed that, in human osteosarcoma cell lines with different metastatic potential, cathepsin L expression levels were constitutively upregulated in the highly metastatic cell line compared with the low metastatic cell line. This phenomenon was also noted for cathepsins D and K. Conversely, cathepsins $\mathrm{B}$ and $\mathrm{H}$ expression levels resulted in downregulation, whereas cathepsin $\mathrm{V}$ was undetectable either in low or in highly metastatic cell lines (Husmann et al., 2008). These findings fit well with earlier observations of Park et al. (1996) who highlighted that cathepsin L was expressed only in $50 \%$ of primary human bone tumors and in $100 \%$ of metastatic tumors. Furthermore, clinical investigations carried out in patients with chondrosarcomas demonstrated that the overexpression of cathepsin L in these tumors was significantly associated with their progression (Söderström et al., 2001). Although these data are suggestive of an active involvement of cathepsin $\mathrm{L}$ in the pathogenesis of metastatic bone disease, the possible mechanisms by which this proteinase could foster this process remain to be fully unraveled. However, experimental evidence, in this regard, highlights that the enzyme could facilitate the homing and the diffusion of metastatic cells into the bone though multiple mechanisms which are summarized in Table 2 . Thus, in vitro studies suggest that cathepsin L secreted by malignant cells can directly facilitate the growth and spread of these cells into the bone by degrading bone matrix proteins (Kawamata et al., 1997; Kirschke et al., 2000; Colella et al., 2004; Erdem et al., 2007; Gocheva and Joyce, 2007; Yang and Cox, 2007; Goo et al., 2009; Kielosto et al., 2009; Ogawa et al., 2009). In addition, the upregulation of osteoclast cathepsin L activity induced by proinflammatory cytokines such as PTH and ILs released from tumor cells could further contribute to degrade bone matrix thus allowing the homing of metastatic cells into the bone tissue (Katunuma et al., 2002a; Kwan Tat et al., 2004; Brage et al., 2005; Everts et al., 2006; Blanchard et al., 2009; Lankelma et al., 2010) (Table 1). Furthermore, this proteinase can indirectly promote bone degradation by triggering the activation latent precursor forms of other proteolytic enzymes, such as MMPs and UPA, which are known to be involved in the metastatic cascade and to modulate bone remodeling (Goretzki et al., 1992; Kawamata et al., 1997; Björklund and Koivunen, 2005; Lah et al., 2006; Wilson and Singh, 2008; Lankelma et al., 2010) (Table 1). Interestingly, recent studies suggested that cathepsin L could also facilitate the diffusion of metastatic cells into the bone through specific mechanisms not related with its bone degrading activity. For instance, it has been shown that, similarly as described for cathepsin B and MMPs, cathepsin L can degrade E-cadherin, an adhesion molecule which is downregulated in metastatic tumor cells, thus enhancing their migratory and invasive ability (Table 2) (Gocheva et al., 2006; Lankelma et al., 2010; Martin et al., 2010; Pontes et al., 2010). These findings could fit well with previous in vitro observations which showed that the inhibition of cathepsin L mRNA and protein expression by antisense oligonucleotides markedly decreased the motility and invasive ability of MNNG/HOS osteosarcoma cells (Krueger et al., 2001). Yet, cathepsin L could contribute to select more aggressive tumor phenotypes by modulating the intracellular 
Table 2 Possible mechanisms by which cathepsin L could facilitate bone metastasis formation.

\begin{tabular}{lll}
\hline Mechanism & \multicolumn{1}{c}{ Effects } & \multicolumn{1}{c}{ References } \\
\hline Bone matrix degradation & Invasion and metastasis & Kawamata et al., 1997; Kirschke et al., 2000; \\
& & Colella et al., 2004; Erdem et al., 2007; \\
& Gocheva and Joyce, 2007; \\
& & Yang and Cox, 2007; Goo et al., 2009; \\
& & Kielosto et al., 2009; Ogawa et al., 2009 \\
$\begin{array}{l}\text { Upregulation of osteoclast } \\
\text { cathepsin L activity induced by } \\
\text { cytokines with bone degrading }\end{array}$ & Bone matrix degradation & Katunuma et al., 2002a; \\
Invasion and metastasis & Kwan Tat et al., 2004; Brage et al., 2005; \\
Everts et al., 2006; Lankelma et al., 2010
\end{tabular}

activity released by tumor cells Activation of latent precursor forms of other proteolytic enzymes involved in the metastatic cascade (MMPs, uPA) Degradation of E-cadherin

Modulation of IGF-I

a) Increased expression of cathepsin $\mathrm{L}$ in endothelial progenitor cells

b) Interactions with VEGF

c) Activation of pro-MMPs and pro-uPA

Extracellular matrix degradation Invasion and metastasis

Reduced adhesion, increased motility and migration of cancer cells

Onset of aggressive tumor phenotype

Tissue remodeling and tumor neovascularization
Goretzki et al., 1992; Kawamata et al., 1997; Björklund and Koivunen, 2005; Lah et al., 2006; Lankelma et al., 2010

Krueger et al., 2001; Gocheva et al., 2006; Lankelma et al., 2010; Pontes et al., 2010

Nakasaki et al., 2008; Navab et al., 2008; Lankelma et al., 2010

Katunuma et al., 2002a,b; Rousselet et al., 2004; Urbich et al., 2005; van Hinsbergh et al., 2006; Keerthivasan et al., 2007;

McMahon and Kwaan, 2008; Chang et al., 2009; Rebbaa et al., 2009;

Deryugina and Quigley, 2010

d) Stimulation of recruitment and activity of blood- or bone marrow-derived cells

expression levels of growth factors and receptors actively involved in bone remodeling such as insulin growth factor I (IGF-I) (Damiens et al., 2000; Nakasaki et al., 2008; Navab et al., 2008; Lankelma et al., 2010). Intriguingly, recent investigations indicated that cathepsin L can indirectly facilitate bone metastasis formation by fostering tumor angiogenesis (Table 1). In support of this hypothesis, Urbich et al. (2005) reported that bone marrow mononuclear cells or circulating blood-derived progenitor cells required cathepsin $\mathrm{L}$ to mediate their invasion activity in vitro and neovascularization improvement in vivo. Furthermore, cytokines which promote bone pit resorption such as TNF- $\alpha$ have been shown to increase the secretion of pro-cathepsin L in bone marrow cells thus enhancing their invasive activity and facilitating the formation of new blood vessels (Furuyama and Fujisawa, 2000a,b; Katunuma et al., 2002a,b). Moreover, van Hinsbergh et al. (2006) recently demonstrated that cathepsin L, in concert with MMP-9, stimulates the recruitment and action of blood- or bone-marrow derived accessory cells that enhance angiogenesis (Table 1). These data are consistent with those findings which suggested that cathepsin L could foster tumor angiogenesis by activating latent forms of proteolytic enzymes, such as MMPs and UPA, implicated in this process (Goretzki et al., 1992; van Hinsbergh et al., 2006; McMahon and Kwaan, 2008; Wilson and Singh, 2008; Deryugina and Quigley, 2010). Interestingly, Keerthivasan et al. (2007) recently showed that, at least in U87MG glioblas- toma cells, vascular endothelial growth factor (VEGF) can upregulate at transcriptional level cathepsin L. Consistent with these observations, Chang et al. (2009) highlighted that in human breast cancer cells, VEGF-A can promote angiogenesis by perturbing the cathepsin-cysteine protease inhibitor balance in venules causing basement membrane degradation. A direct proof of the importance of cathepsin L-VEGF interactions in promoting tumor angiogenesis in different tumors is provided, in part, by some in vitro studies which showed that the inhibition of human procathepsin $\mathrm{L}$ secretion by anti-cathepsin L monoclonal antibody resulted in an inhibition of tumor-induced angiogenesis in highly metastatic human melanoma cells (Rousselet et al., 2004; Frade et al., 2008). Furthermore, Rebbaa et al. (2009) recently demonstrated that Napsul-IIe-Trp-CHO, a specific inhibitor of cathepsin L, inhibited in vitro VEGF secretion by endothelial cell and cathepsin L-mediated degradation of the extracellular matrix. Whereas, in vivo, this molecule was able to inhibit tumor growth in nude mice transplanted neuroblastoma.

\section{Cathepsin L inhibitors in the treatment of cancer related bone disease}

Experimental findings suggestive of an active role of cathep$\sin \mathrm{L}$ in the pathogenesis of metastatic bone disease have led, in recent years, to the development of a series of inhib- 
itors of this proteinase. These molecules, administered in association with antagonists of other proteinases promoting bone metastasis such as cathepsin K and MMPs (Wilson and Singh, 2008), could contribute to elicit a better therapeutic response in the treatment of this pathological condition. Furthermore, these drug combinations might, eventually, overcome the pitfall of the functional redundancy of cathepsin $\mathrm{K}$ and cathepsin L in bone (Nagler and Menard, 2003; Falgueyret et al., 2005; Brix et al., 2008). Another rationale for the development of new specific cathepsin L antagonist relies on the observations that the proteolysis required for tumor invasion occurs mostly extracellularly (Mohamed and Sloane, 2006; Lankelma et al., 2010). This phenomenon could, in part, explain why, during tumor progression, intracellular cathepsin L translocates from lysosomes to the cell membranes and then is actively secreted into the acid extracellular microenvironment of tumors (Chauhan et al., 1998; Katunuma et al., 2002a; Ravanko et al., 2004; Hashimoto et al., 2006; Mohamed and Sloane, 2006; Goo et al., 2009; Ogawa et al., 2009). Therefore, the alternative strategies that can target secreted proteinases such as cathepsin L are actually appealing as the use of molecules which act extracellularly and do not enter cells can overcome potential toxic effects owing to the inhibition of other proteinases present in the lysosomal compartment of normal cells (Hill et al., 1994; Falgueyret et al., 2005; Black and Percival, 2006; Le Gall et al., 2008; Lankelma et al., 2010). This latter phenomenon is, currently, of main concern regarding for instance, the long-term use of some specific inhibitors of cathepsin K in the treatment of bone disease. In fact, these agents, owing to their lysosomotropic nature, by accumulating inside lysosomes, can block the normal activity of other proteinases thus inducing potential adverse effects (Falgueyret et al., 2005; Black and Percival, 2006; Desmarais et al., 2008; Le Gall et al., 2008). In this context, current efforts are specifically directed to design new suitable cathepsin $\mathrm{K}$ inhibitors which could be devoid of these potential side effects (Black and Percival, 2006; Desmarais et al., 2008; Le Gall et al., 2008; Brömme and Lecaille, 2009). Most of the cathepsin L targeted agents which have been developed are a series of different classes of antagonists including small molecule inhibitors with a higher selectivity for cathepsin L (Katunuma et al., 2002a,b; Marquis et al., 2005; Sadaghiani et al., 2007; Myers et al., 2008; Palermo and Joyce, 2008; Yadav et al., 2008; Asaad et al., 2009; Bethel et al., 2009; Long and Chagnovich, 2009; Rebbaa et al., 2009; Kishore Kumar et al., 2010), alternative forms of endogenous inhibitors (Brand et al., 2004; Gianotti et al., 2008), antibodies and antisense oligonucleotides (Krueger et al., 2001; Rousselet et al., 2004; Frade et al., 2008; Long and Chagnovich, 2009) or natural products (Lion et al., 2009; Ogawa et al., 2009). Preclinical studies showed that some of these molecules were effective to inhibit, in vitro, bone matrix digestion at the level of resorption lacuna and to promote bone mineralization, whereas, in vivo, these agents were able to suppress RANKL or M-CSF or TNF- $\alpha$ stimulated bone pit formation and to protect tumor bearing mice from malignant hypercalcemia and to decrease bone metastasis formation (Hill et al., 1994; Katunuma et al., 2002a,b; Brand et al., 2004; Long and Cha- gnovich, 2009). Interestingly, recent investigations have proposed, as a novel approach, to inhibit proteinase-mediated bone resorption, the use of molecules, such as oligogalacturonic acid (OGA) purified from flax pectin which specifically target the collagenase function of proteases involved in cancer progression, including cathepsin L, without affecting their proteolytic activity (Lion et al., 2009). These authors speculated that, owing to the physiological role of human cathepsins and MMPs in bone collagen degradation (Maciewicz et al., 1990; Li et al., 2004; Everts et al., 2006; Charni-Ben Tabassi et al., 2008), OGA, according to its specific mechanism of action, could be of therapeutic benefit in the treatment of disorders associated with an increased bone resorption such as osteolytic bone metastasis (Lion et al., 2009). In addition, owing to its peculiar mechanism, this compound could have therapeutic advantages over classical active site inhibitors regarding their potential side effects. Although the preclinical studies on the effectiveness of cathepsin L inhibitors in preventing bone metastasis formation are promising, there are some valid concerns regarding the clinical use of these molecules. Some of these concerns rely on recent observations that cathepsin L could also act as pro-apoptotic and tumor suppressive molecules (Lah et al., 2006; Di Piazza et al., 2007; Vasiljeva and Turk, 2008; Hsu et al., 2009; Dennemärker et al., 2010; Lankelma et al., 2010). These findings indicate that, in this case, the use of cathepsin L antagonists could be detrimental. However, experimental evidence highlights that, at least in most human tumors, cathepsin L appears to act mainly as tumor promoting proteinase (Zheng et al., 2004, 2008, 2009; Rebbaa et al., 2009), whereas the tumor suppressor activity of this endopeptidase appeared to be restricted only to some squamous cell carcinomas and gliomas (Lah et al., 2006; Di Piazza et al., 2007; Hsu et al., 2009; Dennemärker et al., 2010; Lankelma et al., 2010). Experimental studies indicate that the pro-apoptotic effects of cathepsin $\mathrm{L}$ in these tumors could probably be related to specific functions carried out by this enzyme in the tissue homeostasis of normal counterparts (Lah et al., 2006; Sevenich et al., 2006; Di Piazza et al., 2007; Vasiljeva and Turk, 2008; Hsu et al., 2009; Dennemärker et al., 2010; Lankelma et al., 2010). By contrast, no pro-apoptotic or growth inhibiting activity of cathepsin $\mathrm{L}$ on primary bone tumor cells and in bone metastatic cells has been reported so far.

\section{Conclusion and perspectives}

Growing evidence highlights that cathepsin L, in concert with other proteinases such as cathepsin K, MMPs and uPA, could contribute to promote bone metastasis formation (Katunuma et al., 2002a,b; Navab et al., 2008; Palermo and Joyce, 2008; Wilson and Singh, 2008; Lankelma et al., 2010). These findings imply that the use of a single molecule directed to inhibit a specific target enzyme might not be effective in preventing and/or eradicating bone metastasis. 
Therefore, more effective treatments of this pathological condition should rely on the combination of molecules which can act on different classes of proteolytic enzymes which contribute equally to facilitate the homing and spread of metastatic cells into the bone (Yamamoto et al., 2002; Krol et al., 2003; Palermo and Joyce, 2008; Lion et al., 2009; Long and Chagnovich, 2009; Lankelma et al., 2010). In this scenario, cathepsin L inhibitors could be regarded as additional, potential therapeutic tools in the clinical management of patients with bone metastasis. Furthermore, recent studies which show that cathepsin L appears to act as a pro-survival factor and could contribute to the development of antitumor drug resistance (Zheng et al., 2004; Gocheva et al., 2006; Zajc et al., 2006; Navab et al., 2008; Zheng et al., 2008, 2009; Lankelma et al., 2010) further stress the potential clinical benefit of cathepsin L inhibitors in reverting antitumor drug resistance (Zheng et al., 2004, 2009; Palermo and Joyce, 2008; Rebbaa et al., 2009; Lankelma et al., 2010). Therefore, the combination of cathepsin L antagonists with classical anticancer drugs appears to be a promising therapeutic option also in the treatment of cancer-related bone diseases resistant to conventional antitumor agents (Palermo and Joyce, 2008; Zheng et al., 2008, 2009; Lankelma et al., 2010). Although preclinical studies on the effectiveness of cathepsin L inhibitors in preventing bone metastasis are encouraging, it remains to be established whether these results could be translated to the clinic. Further investigations are needed to better define the pharmacological and toxicological profile of these molecules in humans and their effectiveness in the treatment of metastatic bone disease. These studies could unravel the clinical value of these molecules in the therapeutic management of patients with primary bone cancer and/or skeletal metastasis.

\section{Acknowledgments}

Whenever possible review articles were cited and readers are referred to these review articles for citations of primary papers. We apologize to the many contributors to this field whose work could not be directly cited because of space restrictions. This research was supported by Fondi di Ateneo (ex quota 60\%), Ministero dell' Istruzione, dell’Università e della Ricerca (MIUR), Italy.

\section{References}

- Names of authors and year of publication were changed in the text according to the reference liste•

Abboud-Jarrous, G., Atzmon, R., Peretz, T., Palermo, C., Gadea, B.B., Joyce, J.A., and Vlodavsky, I. (2008). Cathepsin L is responsible for processing and activation of proheparanase through multiple cleavages of a linker segment. J. Biol. Chem. 283, 18167-18176.

Asaad, N., Bethel, P.A., Coulson, M.D., Dawson, J.E., Ford, S.J., Gerhardt, S., Grist, M., Hamlin, G.A., James, M.J., Jones, E.V., et al. (2009). Dipeptidyl nitrile inhibitors of cathepsin L. Bioorg. Med. Chem. Lett. 19, 4280-4283.
Bernard, D., Mehul, B., Thomas-Collignon, A., Simonetti, L., Remy, V., Bernard, M.A., and Schmidt, R. (2003). Analysis of proteins with caseinolytic activity in a human stratum corneum extract revealed a yet unidentified cysteine protease and identified the so called 'stratum corneum thiol protease' as cathepsin L2. J. Invest. Dermatol. 120, 592-600.

Bethel, P.A., Gerhardt, S., Jones, E.V., Kenny, P.W., Karoutchi, G.I., Morley, A.D., Oldham, K., Rankine, N., Augustin, M., Krapp, S., et al. (2009). Design of selective cathepsin inhibitors. Bioorg. Med. Chem. Lett. 19, 4622-4625.

Björklund, M. and Koivunen, E. (2005). Gelatinase-mediated migration and invasion of cancer cells. Biochim. Biophys. Acta 1755, $37-69$.

Black, W.C. and Percival, M.D. (2006). The consequences of lysosomotropism on the design of selective cathepsin $\mathrm{K}$ inhibitors. ChemBioChem 7, 1525-1535.

Blanchard, F., Duplomb, L., Baud'huin, M., and Brounais, B. (2009). The dual role of IL-6-type cytokines on bone remodeling and bone tumors. Cytokine Growth Factor Rev. 20, 19-28.

Brage, M., Abrahamson, M., Lindstrom, V., Grubb, A., and Lerner, U.H. (2005). Different cysteine proteinases involved in bone resorption and osteoclast formation. Calcif. Tissue Int. 76, 439-447.

Brand, H.S., Lerner, U.H., Grubb, A., Beertsen, W., Nieuw Amerongen, A.V., and Everts, V. (2004). Family 2 cystatins inhibit osteoclast-mediated bone resorption in calvarial bone explants. Bone 35, 689-696.

Brix, K., Dunkhorst, A., Mayer, K., and Jordans, S. (2008). Cysteine cathepsins: cellular roadmap to different functions. Biochimie 90, 194-207.

Brömme, D. and Lecaille, F. (2009) Cathepsin K inhibitors for osteoporosis and potential off-target effects. Expert Opin. Investig. Drugs 18, 585-600.

Brömme, D., Li, Z.Q., Barnes, M., and Mehler, E. (1999). Human cathepsin $\mathrm{V}$ functional expression, tissue distribution, electrostatic surface potential, enzymatic characterization, and chromosomal localization. Biochemistry 38, 2377-2385.

Caserman, S., Kenig, S., Sloane, B.F., and Lah, T.T. (2006). Cathepsin L splice variants in human breast cell lines. Biol. Chem. 387, 629-634.

Chang, S.H., Kanasaki, K., Gocheva, V., Blum, G., Harper, J., Moses, M.A., Shih, S.C., Nagy, J.A., Joyce, J., Bogyo, M., et al. (2009). VEGF-A induces angiogenesis by perturbing the cathepsin-cysteine protease inhibitor balance in venules, causing basement membrane degradation and mother vessel formation. Cancer Res. 69, 4537-4544.

Charni-Ben Tabassi, N., Desmarais, S., Bay-Jensen, A.C., Delaisse, J.M., Percival, M.D., and Garnero, P. (2008). The type II collagen fragments Helix-II and CTX-II reveal different enzymatic pathways of human cartilage collagen degradation. Osteoarthr. Cartil. 16, 1183-1191.

Chauhan, S.S., Goldstein, L.J., and Gottesman, M.M. (1991). Expression of cathepsin L in human tumors. Cancer Res. 51, 1478-1481.

Chauhan, S.S., Popescu, N.C., Ray, D., Fleischmann, R., Gottesman, M.M., and Troen, B.R. (1993). Cloning, genomic organization, and chromosomal localization of human cathepsin L. J. Biol. Chem. 268, 1039-1045.

Chauhan, S.S., Ray, D., Kane, S.E, Willingham, M.C., and Gottesman, M.M. (1998). Involvement of carboxy-terminal amino acids in secretion of human lysosomal protease cathepsin L. Biochemistry $37,8584-8594$.

Colella, R., Jackson, T., and Goodwyn, E. (2004). Matrigel invasion 
by the prostate cancer cell lines, PC3 and DU 145, and cathepsin L+B activity. Biotech. Histochem. 79, 121-127.

Collette, J., Bocock, J.P., Ahn, K., Chapman, R.L., Godbold, G., Yeyeodu, S., and Erickson, A.H. (2004). Biosynthesis and alternate targeting of the lysosomal cysteine protease cathepsin L. Int. Rev. Cytol. 241, 1-51.

Czupalla, C., Mansukoski, H., Riedl, T., Thiel, D., Krause, E., and Hoflack, B. (2006). Proteomic analysis of lysosomal acid hydrolases secreted by osteoclasts: implications for lytic enzyme transport and bone metabolism. Mol. Cell. Proteomics 5, 134-143.

Damiens, C., Grimaud, E., Rousselle, A.V., Charrier, C., Fortun, Y., Heymann, D., and Padrines, M. (2000). Cysteine protease production by human osteosarcoma cells (MG63, SAOS2) and its modulation by soluble factors. Cytokine 12, 539-542.

Dennemärker, J., Lohmüller, T., Mayerle, J., Tacke, M., Lerch, M.M., Coussens, L.M., Peters, C., and Reinheckel T. (2010). Deficiency for the cysteine protease cathepsin L promotes tumor progression in mouse epidermis. Oncogene 29, 16111621.๑Please confirm if year, vol. no. and pp. range are correct, as checked on PubMedø

Deryugina, E.I. and Quigley, J.P. (2010). Pleiotropic roles of matrix metalloproteinases in tumor angiogenesis: contrasting, overlapping and compensatory functions. Biochim. Biophys. Acta 1803, 103-120.

Desmarais, S., Black, W.C., Oballa, R., Lamontagne, S., Riendeau, D., Tawa, P., Duong Le, T., Pickarski, M., and Percival, M.D. (2008). Effect of cathepsin K inhibitor basicity on in vivo offtarget activities. Mol. Pharmacol. 73, 147-156.

Di Piazza, M., Mader, C., Geletneky, K., Herrero, Y., Calle, M., Weber, E., Schlehofer, J., Deleu, L., and Rommelaere, J. (2007). Cytosolic activation of cathepsins mediates parvovirus $\mathrm{H}-1$ induced killing of cisplatin and TRAIL-resistant glioma cells. J. Virol. 81, 4186-4198.

Drake, F.H., Dodds, R.A., James, I.E., Connor, J.R., Debouck, C., Richardson, S., Lee-Rykaczewski, E., Coleman, L., Rieman, D., Barthlow, R., et al. (1996). Cathepsin K, but not cathepsins B, $\mathrm{L}$, or $\mathrm{S}$, is abundantly expressed in human osteoclasts. J. Biol. Chem. 271, 12511-12516.

Erdem, N.F., Carlson, E.R., Gerard, D.A., and Ichiki, A.T. (2007). Characterization of 3 oral squamous cell carcinoma cell lines with different invasion and/or metastatic potentials. J. Oral Maxillofac. Surg. 65, 1725-1733.

Everts, V., Korper, W., Hoeben, K.A., Jansen, I.D., Bromme, D., Cleutjens, K.B., Heeneman, S., Peters, C., Reinheckel, T., Saftig, P., et al. (2006). Osteoclastic bone degradation and the role of different cysteine proteinases and matrix metalloproteinases: differences between calvaria and long bone. J. Bone Miner. Res. $21,1399-1408$.

Falgueyret, J.P., Desmarais, S., Oballa, R., Black, W.C., Cromlish, W., Khougaz, K., Lamontagne, S., Masse, F., Riendeau, D., Toulmond, S., et al. (2005). Lysosomotropism of basic cathepsin K inhibitors contributes to increased cellular potencies against offtarget cathepsins and reduced functional selectivity. J. Med. Chem. 48, 7535-7543.

Frade, R., Rousselet, N., and Jean, D. (2008). Intratumoral gene delivery of anti-cathepsin $\mathrm{L}$ single-chain variable fragment by lentiviral vector inhibits tumor progression induced by human melanoma cells. Cancer Gene Ther. 15, 591-604.

Friedrich, B., Jung, K., Lein, M., Türk, I., Rudolph, B., Hampel, G., Schnorr, D., and Loening, S.A. (1999). Cathepsins B, H, L and cysteine protease inhibitors in malignant prostate cell lines, primary cultured prostatic cells and prostatic tissue. Eur. J. Cancer $35,138-144$.
Funkelstein, L., Toneff, T., Mosier, C., Hwang, S.R., Beuschlein, F., Lichtenauer, U.D., Reinheckel, T., Peters, C., and Hook, V. (2008). Major role of cathepsin L for producing the peptide hormones ACTH, beta-endorphin, and alpha-MSH, illustrated by protease gene knockout and expression. J. Biol. Chem. 283, 35652-35659.

Furuyama, N. and Fujisawa, Y. (2000a). Distinct roles of cathepsin $\mathrm{K}$ and cathepsin $\mathrm{L}$ in osteoclastic bone resorption. Endocr. Res. 26, 189-204.

Furuyama, N. and Fujisawa, Y. (2000b). Regulation of collagenolytic protease secretion through c-Src in osteoclasts. Biochem. Biophys. Res. Commun. 272, 116-124.

Gianotti, A., Sommer, C.A., Carmona, A.K., and Henrique-Silva, F. (2008). Inhibitory effect of the sugarcane cystatin CaneCPI-4 on cathepsins B and L and human breast cancer cell invasion. Biol. Chem. 389, 447-453.

Gocheva, V. and Joyce, J.A. (2007). Cysteine cathepsins and the cutting edge of cancer invasion. Cell Cycle 6, 60-64.

Gocheva, V., Zeng, W., Ke, D., Klimstra, D., Reinheckel, T., Peters, C., Hanahan, D., and Joyce, J.A. (2006). Distinct roles for cysteine cathepsin genes in multistage tumorigenesis. Genes Dev. 20, 543-556.

Goo, Y.A., Liu, A.Y., Ryu, S., Shaffer, S.A., Malmstrom, L., Page, L., Nguyen, L.T., Doneanu, C.E., and Goodlett, D.R. (2009). Identification of secreted glycoproteins of human prostate and bladder stromal cells by comparative quantitative proteomics. Prostate 69, 49-61.

Goretzki, L., Schmitt, M., Mann, K., Calvete, J., Chucholowski, N., Kramer, M., Gunzler, W.A., Janicke, F., and Graeff, H. (1992). Effective activation of the proenzyme form of the urokinase-type plasminogen activator (pro-uPA) by the cysteine protease cathepsin L. FEBS Lett. 297, 112-118.

Goto, T., Yamaza, T., and Tanaka, T. (2003). Cathepsins in the osteoclast. J. Electron Microsc. 52, 551-558.

Haeckel, C., Ayala, A.G., Radig, K., Raymond, A.K., Roessner, A., and Czerniak, B. (1999). Protease expression in dedifferentiated parosteal osteosarcoma. Arch. Pathol. Lab. Med. 123, 213-221.

Hagemann, S., Günther, T., Dennemäker, J., Lohmüller, T., Brömme, D., Schüle, R., Peters, C., and Reinheckel, T. (2004). The human cysteine proteinases cathepsin $\mathrm{V}$ can compensate for murine cathepsin L in mouse epidermis and hair follicles. Eur. J. Cell Biol. 83, 775-780.

Harbeck, N., Alt, U., Berger, U., Krüger, A., Thomssen, C., Jänicke, F., Höfler, H., Kates, R.E., and Schmitt, M. (2001). Prognostic impact of proteolytic factors (urokinase-type plasminogen activator, plasminogen activator inhibitor 1 , and cathepsins B, D, and L) in primary breast cancer reflects effects of adjuvant systemic therapy. Clin. Cancer Res. 7, 2757-2764.

Hashimoto, Y., Kondo, C., Kojima, T., Nagata, H., Moriyama, A., Hayakawa, T., and Katunuma, N. (2006). Significance of 32$\mathrm{kDa}$ cathepsin L secreted from cancer cells. Cancer Biother. Radiopharm. 21, 217-224.

Hill, P.A., Buttle, D.J., Jones, S.J., Boyde, A., Murata, M., Reynolds, J.J., and Meikle, M.C. (1994). Inhibition of bone resorption by selective inactivators of cysteine proteinases. J. Cell. Biochem. $56,118-130$.

Hsing, L.C. and Rudensky, A.Y. (2005). The lysosomal cysteine proteases in MHC class II antigen presentation. Immunol. Rev. 207, 229-241.

Hsu, K.F., Wu, C.L., Huang, S.C., Wu, C.M., Hsiao, J.R., Yo, Y.T., Chen, Y.H., Shiau, A.L., and Chou, C.Y. (2009). Cathepsin L mediates resveratrol-induced autophagy and apoptotic cell death in cervical cancer cells. Autophagy 5, 451-460.

Husmann, K., Muff, R., Bolander, M.E., Sarkar, G., Born, W., and 
Fuchs, B. (2008). Cathepsins and osteosarcoma: expression analysis identifies cathepsin $\mathrm{K}$ as an indicator of metastasis. Mol. Carcinog. 47, 66-73.

Ishibashi, O., Inui, T., Mori, Y., Kurokawa, T., Kokubo, T., and Kumegawa, M. (2001). Quantification of the expression levels of lysosomal cysteine proteinases in purified human osteoclastic cells by competitive RT-PCR. Calcif. Tissue Int. 68, 109-116.

Kakegawa, H., Tagami, K., Ohba, Y., Sumitani, K., Kawata, T., and Katunuma, N. (1995). Secretion and processing mechanisms of procathepsin L in bone resorption. FEBS Lett. 370, 78-82.

Katunuma, N., Tsuge, H., Nukatsuka, M., Asao, T., and Fukushima, M. (2002a). Structure-based design of specific cathepsin inhibitors and their application to protection of bone metastases of cancer cells. Arch. Biochem. Biophys. 397, 305-311.

Katunuma, N., Tsuge, H., Nukatsuka, M., and Fukushima, M. (2002b). Structure-based development of cathepsin L inhibitors and therapeutic applications for prevention of cancer metastasis and cancer-induced osteoporosis. Adv. Enzyme Regul. 42, 159172.

Kawamata, H., Nakashiro, K., Uchida, D., Harada, K., Yoshida, H., and Sato, M. (1997). Possible contribution of active MMP2 to lymph-node metastasis and secreted cathepsin L to bone invasion of newly established human oral-squamous-cancer cell lines. Int. J. Cancer 70, 120-127.

Kayser, K., Richter, N., Hufnagl, P., Kayser, G., Kos, J., and Werle, B. (2003). Expression, proliferation activity and clinical significance of cathepsin B and cathepsin L in operated lung cancer. Anticancer Res. 23, 2767-2772.

Keerthivasan, S., Keerthivasan, G., Mittal, S., and Chauhan, S.S. (2007). Transcriptional upregulation of human cathepsin L by VEGF in glioblastoma cells. Gene 399, 129-136.

Keyszer, G., Redlich, A., Häupl, T., Zacher, J., Sparmann, M., Engethüm, U., Gay, S., and Burmester, G.R. (1998). Differential expression of cathepsins B and L compared with matrix metalloproteinases and their respective inhibitors in rheumatoid arthritis and osteoarthritis: a parallel investigation by semiquantitative reverse transcriptase-polymerase chain reaction and immunohistochemistry. Arthritis Rheum. 41, 1378-1387.

Kido, A., Pap, G., Kawate, K., Roessner, A., and Takakura, Y. (2007). Disease-specific expression patterns of proteases in synovial tissues. Pathol. Res. Pract. 203, 451-456.

Kielosto, M., Nummela, P., Jarvinen, K., Yin, M., and Holtta, E. (2009). Identification of integrins $\alpha 6$ and $\beta 7$ as c-Jun- and transformation-relevant genes in highly invasive fibrosarcoma cells. Int. J. Cancer 125, 1065-1073.

Kirschke, H., Eerola, R., Hopsu-Havu, V.K., Brömme, D., and Vuorio, E. (2000). Antisense RNA inhibition of cathepsin L expression reduces tumorigenicity of malignant cells. Eur. J. Cancer 36, 787-795.

Kishore Kumar, G.D., Chavarria, G.E., Charlton-Sevcik, A.K., Arispe, W.M., Macdonough, M.T., Strecker, T.E., Chen, S.E., Siim, B.G., Chaplin, D.J., Trawick, M.L., et al. (2010). Design, synthesis, and biological evaluation of potent thiosemicarbazone based cathepsin L inhibitors. Bioorg. Med. Chem. Lett. 20, 1415-1419.

Kiviranta, R., Morko, J., Alatalo, S.L., NicAmhlaoibh, R., Risteli, J., Laitala-Leinonen, T., and Vuorio, E. (2005). Impaired bone resorption in cathepsin K-deficient mice is partially compensated for by enhanced osteoclastogenesis and increased expression of other proteases via an increased RANKL/OPG ratio. Bone 36, 159-172.

Krol, J., Sato, S., Rettenberger, P., Assfalg-Machleidt, I., Schmitt, M., Magdolen, V., and Magdolen, U. (2003). Novel bi- and tri- functional inhibitors of tumor-associated proteolytic systems. Biol. Chem. 384, 1085-1096.

Krueger, S., Kellner, U., Buehling, F., and Roessner, A. (2001). Cathepsin L antisense oligonucleotides in a human osteosarcoma cell line: effects on the invasive phenotype. Cancer Gene Ther. 8, 522-528.

Kwan Tat, S., Padrines, M., Théoleyre, S., Heymann, D., and Fortun, Y. (2004). IL-6, RANKL, TNF-a/IL-1: interrelations in bone resorption pathophysiology. Cytokine Growth Factor Rev. 15, 49-60.

Lah, T.T., Durán Alonso, M.B., and Van Noorden, C.J. (2006). Antiprotease therapy in cancer: hot or not? Expert Opin. Biol. Ther. 6, 257-279.

Lang, T.H., Willinger, U., and Holzer, G. (2004). Soluble cathepsinL: a marker of bone resorption and bone density? J. Lab. Clin. Med. 144, 163-166.

Lankelma, J.M., Voorend, D.M., Barwari, T., Koetsveld, J., Van der Spek, A.H., De Porto, A.P., Van Rooijen, G., and Van Noorden, C.J. (2010). Cathepsin L, target in cancer treatment? Life Sci. $86,225-233$.

Laurent-Matha, V., Derocq, D., Prebois, C., Katunuma, N., and Liaudet-Coopman, E. (2006). Processing of human cathepsin D is independent of its catalytic function and auto-activation: involvement of cathepsins L and B. J. Biochem. 139, 363-371.

Le Gall, C., Bonnelye, E., and Clezardin, P. (2008). Cathepsin K inhibitors as treatment of bone metastasis. Curr. Opin. Support. Palliat. Care 2, 218-222.

Li, Z., Yasuda, Y., Li, W., Bogyo, M., Katz, N., Gordon, R.E., Fields, G.B., and Bromme, D. (2004). Regulation of collagenase activities of human cathepsins by glycosaminoglycans. J. Biol. Chem. 279, 5470-5479.

Lindeman, J.H., Hanemaaijer, R., Mulder, A., Dijkstra, P.D., Szuhai, K., Bromme, D., Verheijen, J.H., and Hogendoorn, P.C. (2004). Cathepsin $\mathrm{K}$ is the principal protease in giant cell tumor of bone. Am. J. Pathol. 165, 593-600.

Lion, J.M., Mentaverri, R., Rossard, S., Jullian, N., Courtois, B., Courtois, J., Brazier, M., Maziere, J.C., and Kamel, S. (2009). Oligogalacturonic acid inhibit bone resorption and collagen degradation through its interaction with type I collagen. Biochem. Pharmacol. 78, 1448-1455.

Lipton, A. (2007). Treatment of bone metastases and bone pain with bisphosphonates. Support. Cancer Ther. 4, 92-100.

Long, M. and Chagnovich, D. (2009). Use of cathepsin L antagonists in the treatment of bone diseases. WO Patent WO/2009/ 076,490, 2009. Available at: wipo.int.

Luft, F.C. (2009). From furless to heartless-unraveling the diverse functions of cathepsin L. J. Mol. Med. 87, 225-227.

Maciewicz, R.A., Wotton, S.F., Etherington, D.J., and Duance, V.C. (1990). Susceptibility of the cartilage collagens types II, IX and XI to degradation by the cysteine proteinases, cathepsins B and L. FEBS Lett. 269, 189-193.

Marquis, R.W., James, I., Zeng, J., Trout, R.E., Thompson, S., Rahman, A., Yamashita, D.S., Xie, R., Ru, Y., Gress, C.J., et al. (2005). Azepanone-based inhibitors of human cathepsin L. J. Biol. Chem. 48, 6870-6878.

Martin, F.T., Dwyer, R.M., Kelly, J., Khan, S., Murphy, J.M., Curran, C., Miller, N., Hennessy, E., Dockery, P., Barry, F.P., et al. (2010). Potential role of mesenchymal stem cells (MSCs) in the breast tumour microenvironment: stimulation of epithelial to mesenchymal transition (EMT). Breast Cancer Res. Treat. Epub ahead of print; DOI: 10.1007/s10549-010-0734-1.๑•Please update, if

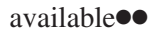

McMahon, B. and Kwaan, H.C. (2008). The plasminogen activator 
system and cancer. Pathophysiol. Haemost. Thromb. 36, 184194.

Mohamed, M.M. and Sloane, B.F. (2006). Cysteine cathepsins: multifunctional enzymes in cancer. Nat. Rev. 6, 764-775.

Montaser, M., Lalmanach, G., and Mach, L. (2002). CA-074, but not its methyl ester CA-074Me, is a selective inhibitor of cathepsin B within living cells. Biol. Chem. 383, 1305-1308.

Mundy, G.R. (2002). Metastasis to bone: causes, consequences and therapeutic opportunities. Nat. Rev. 2, 584-593.

Myers, M.C., Shah, P.P., Beavers, M.P., Napper, A.D., Diamond, S.L., Smith, A.B., III, and Huryn, D.M. (2008). Design, synthesis, and evaluation of inhibitors of cathepsin L: exploiting a unique thiocarbazate chemotype. Bioorg. Med. Chem. Lett. 18, 3646-3651.

Nagler, D.K. and Menard, R. (2003). Family C1 cysteine proteases: biological diversity or redundancy? Biol. Chem. 384, 837-843.

Nakasaki, M., Yoshioka, K., Miyamoto, Y., Sasaki, T., Yoshikawa, H., and Itoh, K. (2008). IGF-I secreted by osteoblasts acts as a potent chemotactic factor for osteoblasts. Bone 43, 869-879.

Nakase, T., Kaneko, M., Tomita, T., Myoui, A., Ariga, K., Sugamoto, K., Uchiyama, Y., Ochi, T., and Yoshikawa, H. (2000). Immunohistochemical detection of cathepsin $\mathrm{D}, \mathrm{K}$, and $\mathrm{L}$ in the process of endochondral ossification in the human. Histochem. Cell Biol. 114, 21-27.

Navab, R., Pedraza, C., Fallavollita, L., Wang, N., Chevet, E., Auguste, P., Jenna, S., You, Z., Bikfalvi, A., Hu, J., et al. (2008). Loss of responsiveness to IGF-I in cells with reduced cathepsin L expression levels. Oncogene 27, 4973-4985.

Ogawa, N., Takahashi, M., Ishidoh, K., and Katunuma, N. (2009). Inhibition of collagenolytic cathepsins by $\beta$-lactoglobulin in milk and its suppressive effect on bone resorption. J. Nutr. Sci. Vitaminol. (Tokyo) 55, 264-270.

Ohsawa, Y., Nitatori, T., Higuchi, S., Kominami, E., and Uchiyama, Y. (1993). Lysosomal cysteine and aspartic proteinases, acid phosphatase, and an endogenous cysteine proteinase inhibitor, cystatin-beta, in rat osteoclasts. J. Histochem. Cytochem. 41, 1075-1083.

Palermo, C. and Joyce, J.A. (2008). Cysteine cathepsin proteases as pharmacological targets in cancer. Trends Pharmacol. Sci. 29, 22-28.

Pang, M., Martinez, A.F., Jacobs, J., Balkan, W., and Troen, B.R. (2005). RANK ligand and interferon $\gamma$ differentially regulate cathepsin gene expression in pre-osteoclastic cells. Biochem. Biophys. Res. Commun. 328, 756-763.

Park, I.C., Lee, S.Y., Jeon, D.G., Lee, J.S., Hwang, C.S., Hwang, B.G., Lee, S.H., Hong, W.S., and Hong, S.I. (1996). Enhanced expression of cathepsin L in metastatic bone tumors. J. Korean Med. Sci. 11, 144-148.

Perez-Amodio, S., Jansen, D.C., Schoenmaker, T., Vogels, I.M., Reinheckel, T., Hayman, A.R., Cox, T.M., Saftig, P., Beertsen, W., and Everts, V. (2006). Calvarial osteoclasts express a higher level of tartrate-resistant acid phosphatase than long bone osteoclasts and activation does not depend on cathepsin $\mathrm{K}$ or $\mathrm{L}$ activity. Calcif. Tissue Int. 79, 245-254.

Pontes, J., Jr., Srougi, M., Borra, P.M., Dall'Oglio, M.F., RibeiroFilho, L.A., and Leite, K.R. (2010). E-cadherin and beta-catenin loss of expression related to bone metastasis in Prostate Cancer. Appl. Immunohistochem. Mol. Morphol. 18, 179-184••Please confirm if first author name, year, vol. no. and pp. range are correct, as checked on PubMed. Citations within the text/tables

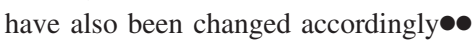

Potts, W., Bowyer, J., Jones, H., Tucker, D., Freemont, A.J., Millest, A., Martin, C., Vernon, W., Neerunjun, D., Slynn, G., et al. (2004). Cathepsin L-deficient mice exhibit abnormal skin and bone development and show increased resistance to osteoporosis following ovariectomy. Int. J. Exp. Pathol. 85, 85-96.

Ravanko, K., Jarvinen, K., Helin, J., Kalkkinen, N., and Hölttä, E. (2004). Cysteine cathepsins are central contributors of invasion by cultured adenosylmethionine decarboxylase-transformed rodent fibroblasts. Cancer Res. 64, 8831-8838.

Rawlings, N.D., Barrett, A.J., and Bateman, A. (2010). MEROPS: the peptidase database. Nucleic Acids Res. 38 (database issue), D227-D233. DOI: 10.1093/nar/gkp971.

Rebbaa, A., Chu, F., Sudha, T., Gallati, C., Dier, U., Dyskin, E., Yalcin, M., Bianchini, C., Shaker, O., and Mousa, S.A. (2009). The anti-angiogenic activity of NSITC, a specific cathepsin L inhibitor. Anticancer Res. 29, 4473-4481.

Reinheckel, T., Deussing, J., Roth, W., and Peters, C. (2001). Towards specific functions of lysosomal cysteine peptidases: phenotypes of mice deficient for cathepsin B or cathepsin L. Biol. Chem. 382, 735-741.

Rifkin, B.R., Vernillo, A.T., Kleckner, A.P., Auszmann, J.M., Rosenberg, L.R., and Zimmerman, M. (1991). Cathepsin B and L activities in isolated osteoclasts. Biochem. Biophys. Res. Commun. 179, 63-69.

Rousselet, N., Mills, L., Jean, D., Tellez, C., Bar-Eli, M., and Frade, R. (2004) Inhibition of tumorigenicity and metastasis of human melanoma cells by anti-cathepsin $\mathrm{L}$ single chain variable fragment. Cancer Res. 64, 146-151.

Rousselle, A.V., Damiens, C., Grimaud, E., Fortun, Y., Padrines, M., Passuti, N., and Heymann, D. (2001). Potential synergies between matrix proteins and soluble factors on resorption and proteinase activities of rabbit bone cells. Histol. Histopathol. 16, 727-734.๑This reference is not cited in the text. Please cite reference or delete it from the list $\bullet$

Russo, A., Bazan, V., Gebbia, N., Pizzolanti, G., Tumminello, F.M., Dardanoni, G., Ingria, F., Restivo, S., Tomasino, R.M., and Leto, G. (1995). Flow cytometric DNA analysis and lysosomal cathepsins B and L in locally advanced laryngeal cancer. Relationship with clinicopathologic parameters and prognostic significance. Cancer 76, 1757-1764.

Sadaghiani, A.M., Verhelst, S.H., Gocheva, V., Hill, K., Majerova, E., Stinson, S., Joyce, J.A., and Bogyo, M. (2007). Design, synthesis, and evaluation of in vivo potency and selectivity of epoxysuccinyl-based inhibitors of papain-family cysteine proteases. Chem. Biol. 14, 499-511.

Schedel, J., Seemayer, C.A., Pap, T., Neidhart, M., Kuchen, S., Michel, B.A., Gay, R.E., Muller-Ladner, U., Gay, S., and Zacharias, W. (2004). Targeting cathepsin L (CL) by specific ribozymes decreases CL protein synthesis and cartilage destruction in rheumatoid arthritis. Gene Ther. 11, 1040-1047.

Schurigt, U., Hummel, K.M., Petrow, P.K., Gajda, M., Stockigt, R., Middel, P., Zwerina, J., Janik, T., Bernhardt, R., Schuler, S., et al. (2008). Cathepsin K deficiency partially inhibits, but does not prevent, bone destruction in human tumor necrosis factortransgenic mice. Arthritis Rheum. 58, 422-434.

Sevenich, L., Pennacchio, L.A., Peters, C., and Reinheckel, T. (2006). Human cathepsin L rescues the neurodegeneration and lethality in cathepsin B/L double-deficient mice. Biol. Chem. 387, 885-891.

Söderström, M., Ekfors, T., Bohling, T., Aho, A., Aro, H.T., and Vuorio, E. (2001). Cysteine proteinases in chondrosarcomas. Matrix Biol. 19, 717-725.

Solau-Gervais, E., Zerimech, F., Lemaire, R., Fontaine, C., Huet, G., and Flipo, R.M. (2007). Cysteine and serine proteases of synovial tissue in rheumatoid arthritis and osteoarthritis. Scand. J. Rheumatol. 36, 373-377. 
Spens, E. and Haggstrom, L. (2005). Protease activity in proteinfree NS0 myeloma cell cultures. In vitro Cell. Dev. Biol. 41, $330-336$.

Stoka, V., Turk, V., and Turk, B. (2007). Lysosomal cysteine cathepsins: signaling pathways in apoptosis. Biol. Chem. 388, 555560.

Tagami, K., Kakegawa, H., Kamioka, H., Sumitani, K., Kawata, T., Lenarcic, B., Turk, V., and Katunuma, N. (1994). The mechanisms and regulation of procathepsin $\mathrm{L}$ secretion from osteoclasts in bone resorption. FEBS Lett. 342, 308-312.

Tumminello, F.M., Leto, G., Pizzolanti, G., Candiloro, V., Crescimanno, M., Crosta, L., Flandina, C., Montalto, G., Soresi, M., Carroccio, A., et al. (1996) Cathepsin D, B and L circulating levels as prognostic markers of malignant progression. Anticancer Res. 16, 2315-2319.

Turk, V., Stoka, V., and Turk, D. (2008). Cystatins: biochemical and structural properties, and medical relevance. Front. Biosci. 13, $5406-5420$.

Urbich, C., Heeschen, C., Aicher, A., Sasaki, K., Bruhl, T., Farhadi, M.R., Vajkoczy, P., Hofmann, W.K., Peters, C., Pennacchio, L.A., et al. (2005). Cathepsin L is required for endothelial progenitor cell-induced neovascularization. Nat. Med. 11, 206-213.

Uusitalo, H., Hiltunen, A., Soderstrom, M., Aro, H.T., and Vuorio, E. (2000). Expression of cathepsins B, H, K, L, and S and matrix metalloproteinases 9 and 13 during chondrocyte hypertrophy and endochondral ossification in mouse fracture callus. Calcif. Tissue Int. 67, 382-390.

van Hinsbergh, V.W., Engelse, M.A., and Quax, P.H. (2006). Pericellular proteases in angiogenesis and vasculogenesis. Arterioscler. Thromb. Vasc. Biol. 26, 716-728.

Vasiljeva, O. and Turk, B. (2008). Dual contrasting roles of cysteine cathepsins in cancer progression: apoptosis versus tumour invasion. Biochimie 90, 380-386.

Wilson, T.J. and Singh, R.K. (2008). Proteases as modulators of tumor-stromal interaction: primary tumors to bone metastases. Biochim. Biophys. Acta 1785, 85-95.

Yadav, M.R., Shinde, A.K., Chouhan, B.S., Giridhar, R., and Menard, R. (2008). Peptidomimetic 2-cyanopyrrolidines as potent selective cathepsin L inhibitors. J. Enzyme Inhib. Med. Chem. 23, 190-197.
Yamamoto, M., Ikeda, S., Kondo, H., and Inoue, S. (2002). Design and synthesis of dual inhibitors for matrix metalloproteinase and cathepsin. Bioorg. Med. Chem. Lett. 12, 375-378.

Yang, Z. and Cox, J.L. (2007). Cathepsin L increases invasion and migration of B16 melanoma. Cancer Cell Int. 7, 8.

Yasothornsrikul, S., Greenbaum, D., Medzihradszky, K.F., Toneff, T., Bundey, R., Miller, R., Schilling, B., Petermann, I., Dehnert, J., Logvinova, A., et al. (2003). Cathepsin L in secretory vesicles functions as a prohormone-processing enzyme for production of the enkephalin peptide neurotransmitter. Proc. Natl. Acad. Sci. USA 100, 9590-9595.

Yasuda, Y., Li, Z., Greenbaum, D., Bogyo, M., Weber, E., and Brömme, D. (2004). Cathepsin V, a novel potent elastolytic activity expressed in activated macrophages. J. Biol. Chem. 279, 36761-36770.

Zajc, I., Sever, N., Bervar, A., and Lah, T.T. (2002). Expression of cysteine peptidase cathepsin L and its inhibitors stefins $A$ and $\mathrm{B}$ in relation to tumorigenicity of breast cancer cell lines. Cancer Lett. 187, 185-190.

Zajc, I., Hreljac, I., and Lah, T. (2006). Cathepsin L affects apoptosis of glioblastoma cells: a potential implication in the design of cancer therapeutics. Anticancer Res. 26, 3357-3364.

Zheng, X., Chou, P.M., Mirkin, B.L., and Rebbaa, A. (2004). Senescence-initiated reversal of drug resistance: specific role of cathepsin L. Cancer Res. 64, 1773-1780.

Zheng, X., Chu, F., Mirkin, B.L., Sudha, T., Mousa, S.A., and Rebbaa, A. (2008). Role of the proteolytic hierarchy between cathep$\sin$ L, cathepsin D and caspase-3 in regulation of cellular susceptibility to apoptosis and autophagy. Biochim. Biophys. Acta 1783, 2294-2300.

Zheng, X., Chu, F., Chou, P.M., Gallati, C., Dier, U., Mirkin, B.L., Mousa, S.A., and Rebbaa, A. (2009). Cathepsin L inhibition suppresses drug resistance in vitro and in vivo: a putative mechanism. Am. J. Physiol. 296, C65-C74.

Zavasnik-Bergant, T. and Turk, B. (2007). Cysteine proteases: destruction ability versus immunomodulation capacity in immune cells. Biol. Chem. 388, 1141-1149.

Received December 23, 2009; accepted March 2, 2010 